\title{
A LONG-TERM REVIEW OF SHELF ARTHROPLASTY
}

\author{
BRUCE R. T. LOVE, PETER M. STEVENS, PETER F. WILLIAMS
}

From the Department of Orthopaedic Surgery, Royal Children's Hospital, Melbourne

\begin{abstract}
Shelf arthroplasty is briefly reviewed in historical perspective and the results in $\mathbf{4 5}$ hips (39 patients) which had undergone this procedure at the Royal Children's Hospital are presented. The majority of these patients were adolescents who had previously been treated for congenital dislocation or subluxation of the hip. The indications for operation and the operative technique are discussed. Clinical examination was carried out upon 33 of the 39 patients at an average of 11 years after operation. The results suggested that where pain had been an indication for operation almost 80 per cent of the hips remained relatively free of symptoms at the time of follow-up and in those patients where acetabular dysplasia had been an indication, the coverage remained good and pain had not appeared. It is concluded that the shelf operation is useful for dealing with both pain and dysplasia in the adolescent.
\end{abstract}

Persistent acetabular dysplasia may permit progressive subluxation of the femoral head. The mechanics of the joint are compromised due to an inadequate fulcrum and a shortened abductor lever arm, and this is manifest by a Trendelenburg gait and symptoms of fatigue. The diminished weight-bearing area and increased shear stress cause attrition of hyaline cartilage and, ultimately, degenerative arthritis and pain.

This vicious cycle may be broken by an appropriately timed shelf arthroplasty which may provide lasting relief of symptoms. The shelf is an extra-articular bony buttress which, by altering the slope of the acetabulum, prevents lateral or upward migration of the femoral head. When placed low and parallel to the femoral neck, it reinforces the anterolateral capsule; theoretically, metaplasia of the capsule provides fibrocartilage, effectively increasing the acetabular surface area that is capable of bearing weight. By stabilising the fulcrum, the mechanics of the joint are also improved.

Konig (1891) is credited with the first reported shelf arthroplasty. Albee (1919) described his "bone graft wedge remodelling operation" to treat the shallow acetabulum which often resulted from congenital dislocation of the hip, and cited its advantages over the intra-articular acetabuloplasty proposed by Hoffa (1905). He stressed that all contractures should be overcome by manipulation before operation or by open division. The operative technique consisted of a semicircular osteotomy just above the capsule, and then a "bucket handle" of acetabular rim was levered down and held in position by pegs of tibial bone (Fig. 1). The anterolateral capsule was also reefed with kangaroo tendon sutures. After operation the patient spent eight weeks in a plaster spica.
Ghormley (1931) presented an extensive review of the literature along with his indications, which mainly consisted of subluxation from infantile paralysis or

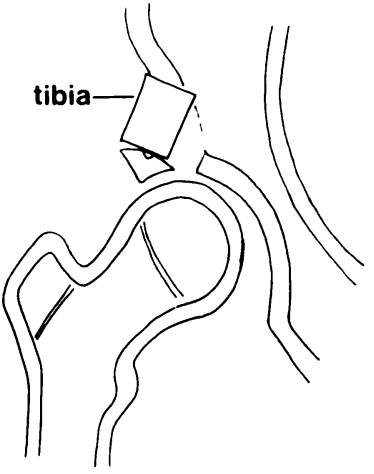

ALBEE 1919

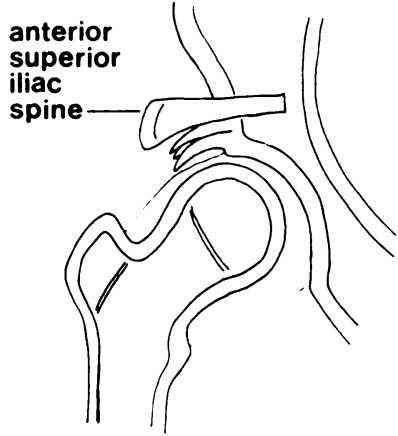

GHORMLEY 1931

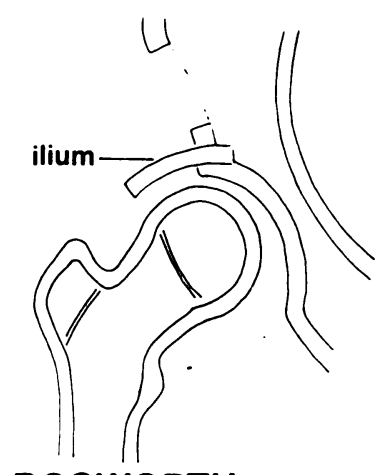

BOSWORTH before 1946

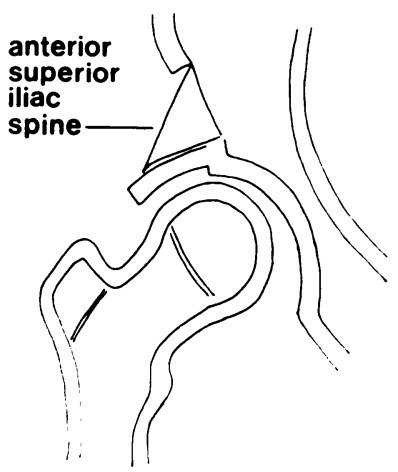

WILSON 1974
Fig. 1

Various techniques for performing a shelf arthroplasty.
B. R. T. Love, FRACS, Orthopaedic Registrar P. M. Stevens, MD, Orthopaedic Fellow

P. F. Williams, FRCS, FRACS, Chief Orthopaedic Surgeon Requests for reprints should be sent to Mr B. R. T. Love.
The Department of Orthopaedic Surgery, Royal Children's Hospital, Flemington Road, Parkville, Victoria 3052, Australia 


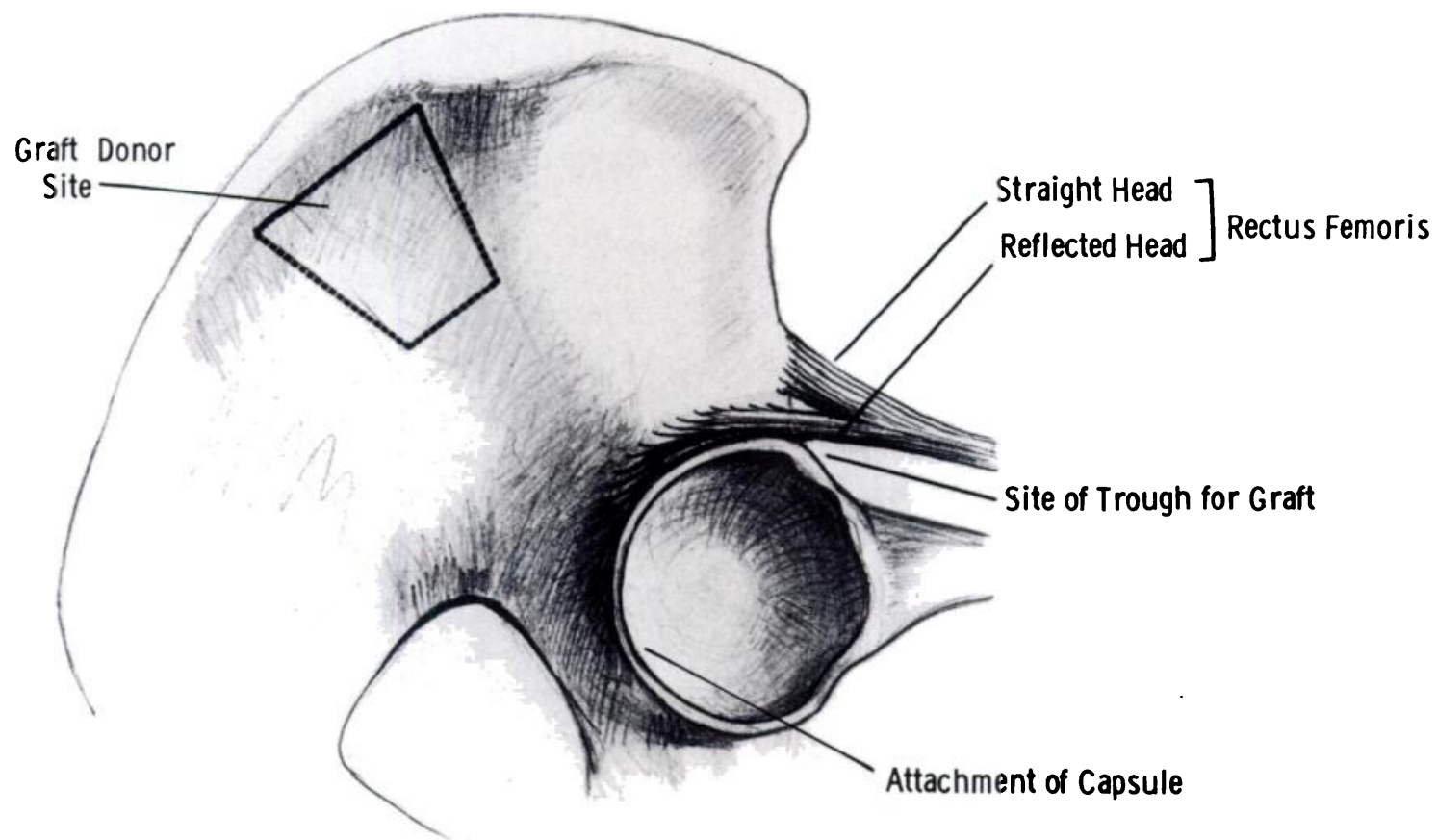

Fig. 2

Drawing to show the location of the trough for the graft situated between the capsule of the hip joint and the reflected head of rectus femoris. The graft donor site is also shown.

congenital dislocation of the hip. He stated that success depended on reduction of the hip by heavy traction and the provision of a large shelf, providing maximal cover but not compromising abduction by impingement on the trochanter. He preferred to reflect osteoperiosteal "bone chips" downward and wedge the anterior superior iliac spine in above these to hold them in place (Fig. 1). After operation his treatment was identical to that of Albee.

Bosworth et al. (1961) reviewed 46 shelf procedures over a period of 24 years. The age range was 18 to 54 years with a mean age of 35 at the time of operation. Their indications included pain, instability, or both. It is apparent that this shelf operation was used both for prophylaxis and for the treatment of secondary osteoarthritis. Before 1946 they reflected a flap of outer ilium, packing bone chips above it and using heavy sutures to secure the shelf. There was a high incidence of proximal displacement of the graft. They therefore modified the technique by driving a large rectangular iliac graft obliquely into a prepared slot just above the acetabular margin and this was held in place by the reflected head of the rectus and the gluteal muscles (Fig. 1). No plaster was used and partial weight-bearing was permitted by the fourth week.

Heyman (1963) reported on 35 shelf procedures of the Bosworth type, carried out in cases of cerebal palsy and myelodysplasia as well as in congenital dislocation of the hip. Recently, the Czechoslovakians have reported favourable results in 113 patients, using the Bosworth technique (Lomicek, Stryhal and Cech 1977).

Wilson (1974) related his experience with 19 shelf procedures (Fig. 1). He emphasised that this operation was most useful for treating failure of adequate acetabular development in early adolescence. He favoured the Salter or Pemberton procedures for children aged 3 to 10 years. Over the age of about 20 years, the shelf is less likely to be successful and has been largely superseded by other reconstructive procedures.

For over 30 years, the staff at the Royal Children's Hospital have performed a type of shelf arthroplasty modified from the technique of Bosworth. It was considered timely that an attempt be made to contact these patients for review and the records of those operated on since 1958 were surveyed. The aim was to assess the long-term results of the procedure as a method of relieving symptoms and of avoiding symptoms later in life and also to derive exact indications for its use. The operative technique has not altered significantly in the period that the procedure has been performed at this hospital.

\section{MATERIAL AND METHODS}

Shelf arthroplasty had been performed on more than 50 patients in the last 20 years at the Royal Children's Hospital, Melbourne. If adequate case notes were not available, the patient was excluded from the review. Thirty-nine of these patients were reviewed: 20 were personally interviewed and examined, six of whom had had bilateral arthroplasties, 13 others had been seen by a member of the staff within the preceding year and their records were considered adequate, and the remaining six were reviewed by questionnaire.

The following information was obtained: the age at presentation, the symptoms, the primary diagnosis, and treatment; the age at operation, the indications for shelf arthroplasty, and its early results; and the age at review and the interval since operation. The current 
status regarding symptoms of pain, limp, stiffness or other complaints were sought, in particular the limitation of activity. Using the Wrightington Hospital chart, the physical findings were recorded: the range of movement, tenderness, the presence of Trendelenburg's sign and discrepancy in leg length. Original radiographs were not always available: all patients with significant symptoms had had recent radiographs performed or further radiographs were taken, but a number of patients without symptoms declined further radiography. Operative technique. The patient is placed supine on the operating table with a sandbag under the affected hip. Adrenaline is used to infiltrate the line of the incision which corresponds to the standard skin incision of Salter. The skin and deep fascia are divided in the line of the incision, taking care to avoid the lateral cutaneous nerve of the thigh. An incision is made through the periosteum onto the wing of the ilium, and the tensor fasciae latae, gluteus minimus and gluteus medius are stripped subperiosteally from the outer lip of the ilium almost as far as the greater sciatic notch. Haemostasis is obtained using diathermy. The dissection is continued to the straight head of rectus femoris. The reflected head of rectus femoris is then exposed and used as a guide for determining the precise level of the graft. A gouge is then used to cut a trough in the plane between the capsule and the reflected head of rectus femoris (Fig. 2). Because the femoral neck is frequently anteverted it is important that the graft be located anterosuperiorly to the capsule. The gouge may tend to slide posteriorly if care is not taken. This trough should be about $3 / 16$ inch $(0.5$ centimetre $)$ in width and 1.5 inches ( 3.8 centimetres) in length. It needs to be cut slightly upwards and medially, so that the graft will adequately cover the femoral head. A wedge-shaped graft the same width as the trough is then taken from the curved wing of the ilium above the site of the trough: to do this the crest of the ilium is reflected medially in order to expose the cancellous bone of the iliac crest, two vertical incisions are then made in the ilium and a full-thickness graft is taken. The graft is then hammered into the trough making sure it is a secure fit and immobile within the trough. A suction drain is inserted and the wound closed in layers taking care to pull the gluteal muscles tightly over the inserted graft.

After-care. The drain is removed at 48 hours. The patient remains in bed for about 10 days. Mobilisation is then allowed on crutches but the patient is not permitted to bear weight until there is evidence of union of the graft, usually in about nine weeks in the adolescent.

\section{ANALYSIS AT REVIEW}

Primary diagnosis and treatment. In all but two patients the diagnosis of congenital dislocation of the hip or congenital subluxation of the hip had been made. Thirty-seven hips had had conservative treatment only; in one of these avascular necrosis resulted, but the outcome is currently satisfactory. Three had had an open reduction, one of which underwent a subsequent Salter osteotomy. Femoral derotation had been performed on three hips. Two patients had had poliomyelitis; one had a painful hip and the other a dysplastic one. The painful hip did not get relief from operation and has since been arthrodesed.

Indications for operation. The principal indications were pain or radiological dysplasia, or both. In eight hips, a limp was considered to be one of the indications but in all eight it was associated with pain. The indication was pain or pain and limp in 20 hips, dysplasia or subluxation in 14 , and both dysplasia and pain in 11. The pain described was typically fatigue pain where discomfort was at a maximum towards the end of activities or the end of the day.
The average age at the time of operation was 12 years with a range from 6 to 22 years.

\section{Results of operation}

Immediate results. Pain persisted in two hips: in the first, the pain gradually settled over two years; in the second, it was made worse by operation but it also settled over a two-year period. Where the indication for operation was dysplasia, pain did not occur after operation.

Long-term results. The age at follow-up varied from 14 to 30 years with an average of 24 years. The intervals since operation ranged from 2 to 20 years with an average follow-up period of 11 years.

Pain. Thirty-eight hips were considered to be satisfactory (Table I). Although six of these had an occasional ache, this did not interfere with daily activities of the

Table I. Results of shelf arthroplasty related to indication

\begin{tabular}{|lr|c|c|c|c|}
\hline \multirow{2}{*}{\multicolumn{1}{|c|}{ Indications }} & & \multicolumn{5}{|c|}{ Results } \\
\cline { 3 - 6 } & No pain & $\begin{array}{c}\text { Minimal } \\
\text { pain }\end{array}$ & $\begin{array}{c}\text { Moderate } \\
\text { pain }\end{array}$ & $\begin{array}{c}\text { Severe } \\
\text { pain }\end{array}$ \\
\hline Pain & 12 & 8 & 1 & - & 3 \\
Pain and limp & 8 & 3 & 1 & 4 & - \\
Pain and dysplasia & 11 & 5 & 1 & 1 & 4 \\
Dysplasia & 14 & 11 & 3 & - & - \\
\hline
\end{tabular}

Minimal pain: no interference with daily activities, pain relief never required.

Moderate pain: some restriction of activity, rest, simple analgesia. Severe pain: further operation been performed or being considered.

patient and no specific measures were ever required for relief of pain. Five of these hips gave moderate pain, but in none did this cause the patient to seek further advice. Occasional restriction of activity was necessary in this group; rest, simple analgesia or simple avoidance of prolonged walking was usually all that was required to give them relief.

The remaining seven hips gave more severe pain: three had undergone total hip replacement because of its severity, one underwent an arthrodesis and from one an area of osteochondritis dissecans was removed. Plans had been made for total hip replacement for one of the other hips, and the remaining hip was simply under observation.

Limp. Twenty of the 45 hips were associated with a distinct limp at review and a positive Trendelenburg's sign was present in 16. Most of these patients felt that although the limp was of concern to them, it did not interfere significantly with their normal daily activities. Range of movement. With the exception of the hip that had been arthrodesed, all hips had almost a full range of movement as compared to the normal side, except where bilateral operations had been performed. Fixed flexion deformity of up to 10 degrees was noted in seven 
hips and the maximal loss of range of movement in any one hip as compared to the other side was 20 degrees-this particular patient was currently free of symptoms but had no medial rotation of the affected hip.

If the results are considered in relation to indication for operation, a clear pattern emerges (Table I). Where pain was part of the indication and persisted in a severe form further operations were required; where symptoms were only mild or moderate no further advice was sought. Where dysplasia alone or subluxation was the indication no patient required a further operation, although three had an occasional ache.

Radiology. Radiographs were taken of those patients who consented. In patients whose hips were free of pain, less than half of those reviewed underwent radiography.

Where radiographs were available the majority of hips showed early hypertrophy of the shelf. This suggested that it was functioning in its load-bearing capacity. Once early hypertrophy had occurred the radiological appearance of the graft remained static.

Because of the nature of the procedure and the. variable effect on joint space, no conclusions could be drawn from measuring this space. However, it seemed that there was a narrower joint space in relation to the graft in symptomatic hips that required further operation than in non-symptomatic hips.

An assessment of the amount of cover of the femoral head was made by measuring the width of the femoral head and then, as a fraction, the distance by which the lateral margin of the femoral head protruded beyond the lateral margin of the shelf. Of the 11 non-symptomatic hips for which radiographs were available, five had one-third uncovered and six had complete cover (Figs 3 to 5). Of those hips in which

symptoms were present, the maximal amount of uncovering was half the width of the femoral head, but in the majority only one-third of the femoral head was uncovered. The degree of uncovering did not relate to the severity of symptoms. In no case had there been absorption of the shelf.

\section{DISCUSSION}

The results of the study clearly suggest that where pain is an indication for surgery, almost 80 per cent will remain relatively free of symptoms over many years. The results of operative intervention where dysplasia is an indication show that pain has not appeared as a troublesome symptom. What is unknown is whether pain would have appeared in some of these hips in which dysplasia had been considered an indication if no operative intervention had taken place.

The results compare favourably with other published series. The relatively uncomplicated nature of the operation gives it a great advantage over the Chiari osteotomy, especially as the latter frequently produces a more pronounced limp. Where the procedure has been carried out on a patient over the age of 10 years no resorption of the graft has occurred; even over a period of 20 years little change seems to take place in the shape of the graft once the initial remodelling and hypertrophy has occurred (Figs 6 to 9).

It is difficult to estimate what part is played by dysplasia of the femoral head in the late deterioration of these hips and there is no evidence from this series that those with more or less dysplasia had a better or worse prognosis.

Discussion with the surgeons who have performed

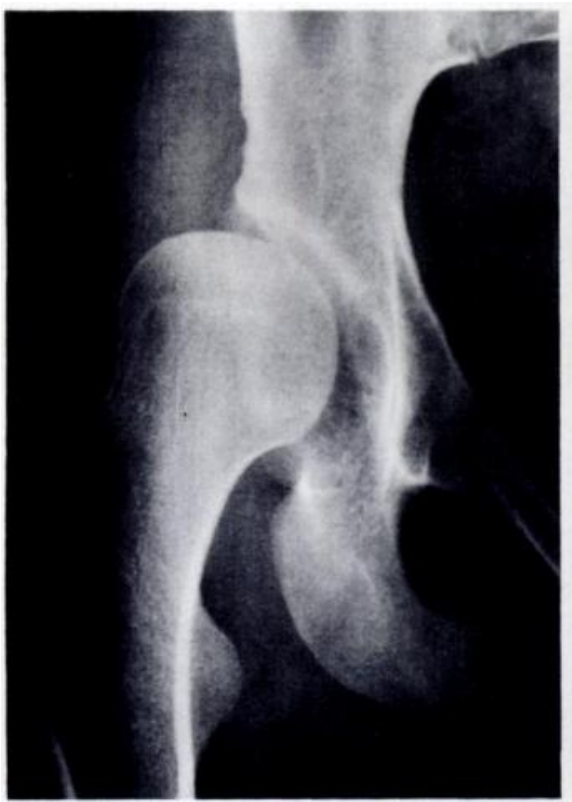

Fig. 3

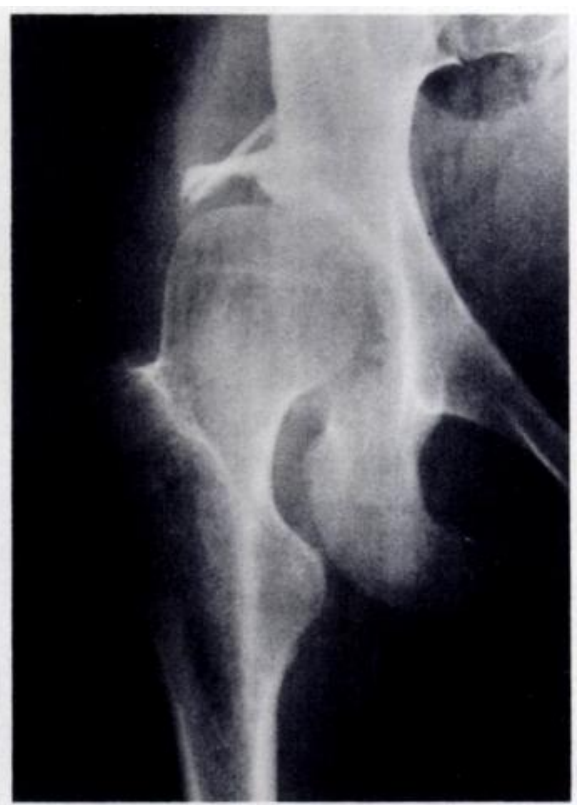

Fig. 4

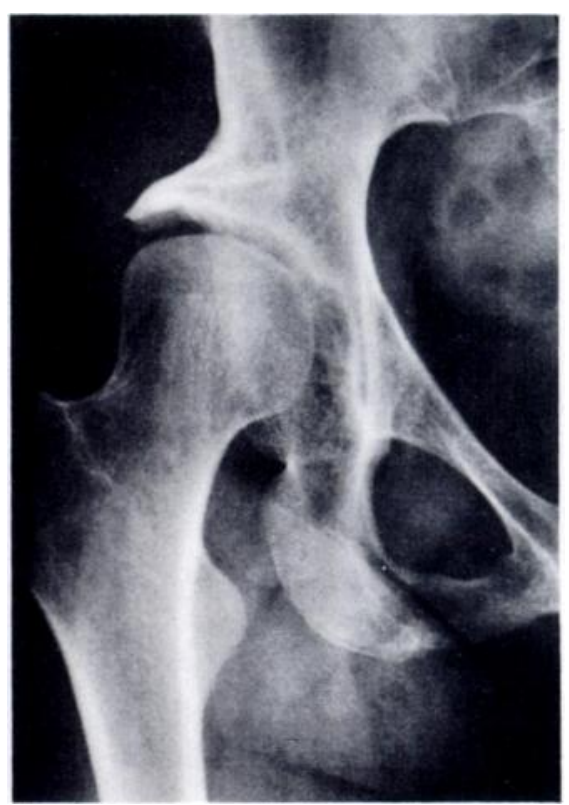

Fig. 5

Figure 3-Radiograph showing poorly covered femoral head in a 15 -year-old girl suffering from fatigue pain in the hips. Figure 4-The graft 12 months after operation. Figure 5-Fourteen years later the graft has hypertrophied giving complete cover of the femoral head. The patient is asymptomatic. 


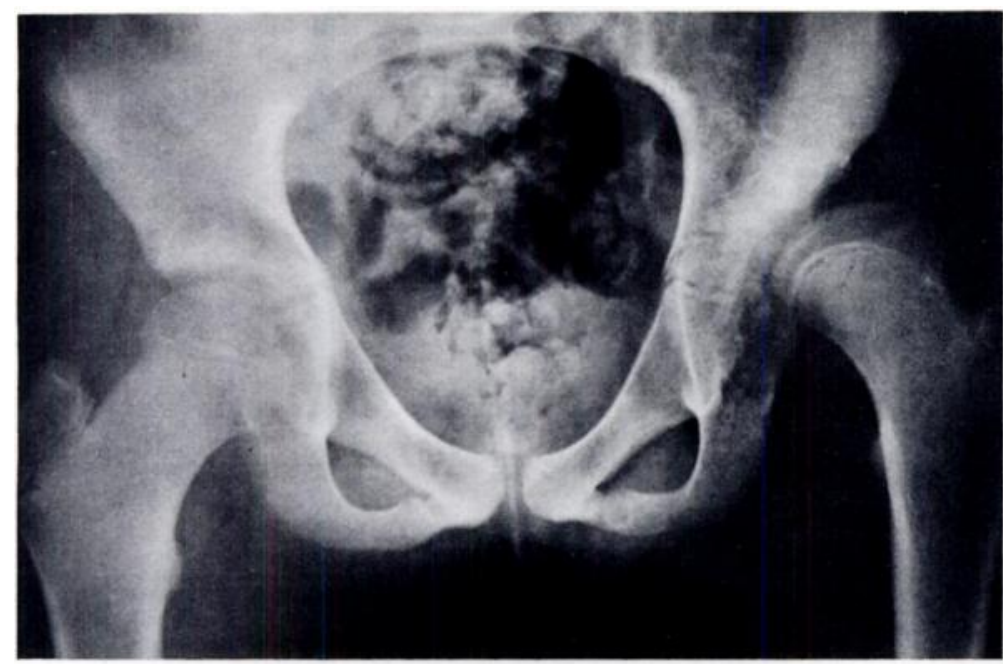

Fig. 6

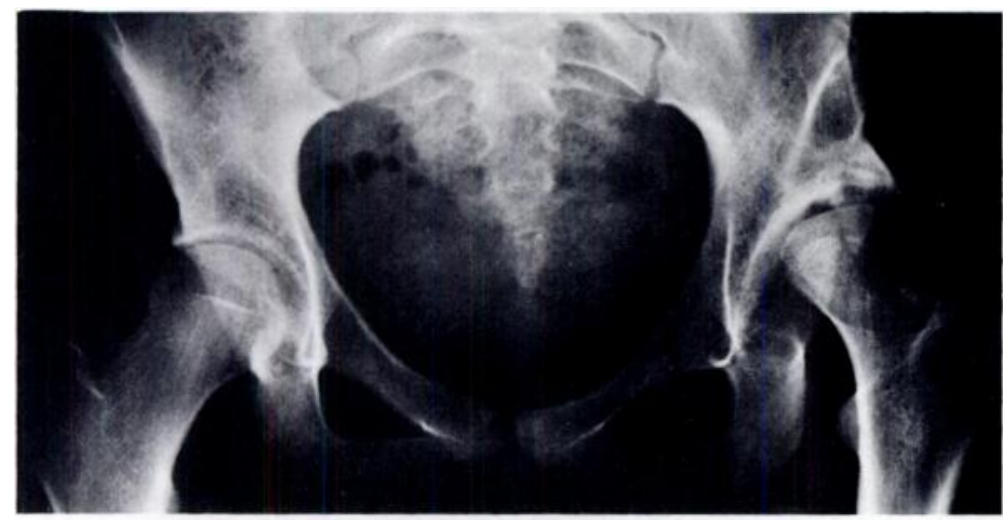

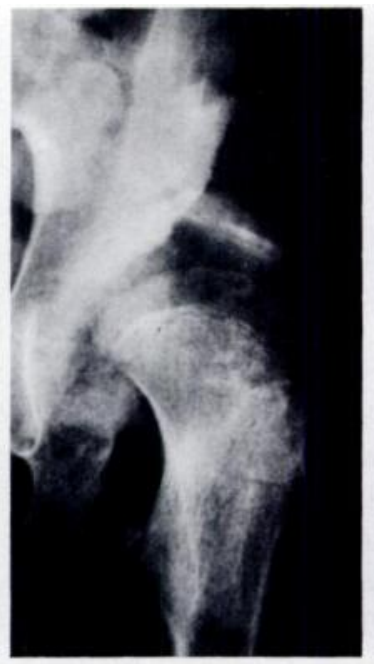

Fig. 7

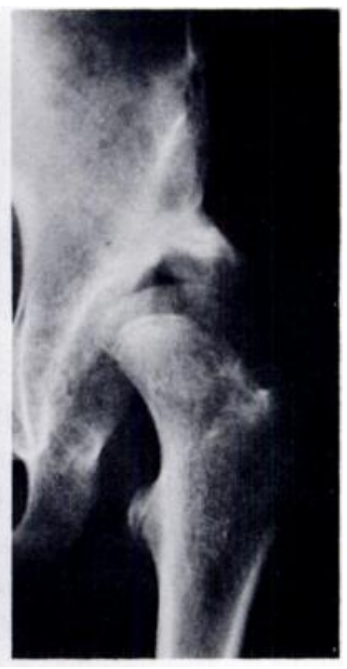

Fig. 8

Fig. 9

Figure 6-An 11-year-old girl with symptomatic subluxation of the left hip as a sequel to congenital dislocation. Figure 7-Radiograph immediately after operation demonstrating the optimal size and placement of the iliac graft. Figure 8-At 14 months after operation the graft is well incorporated. Figure 9-At the age of 16 (five years after operation) the patient remains asymptomatic. There is further remodelling of the graft without resorption and the joint space is well maintained.

total hip replacement on those cases in which disabling symptoms supervene suggested that the shelf was an adequate superior buttress for seating the new acetabulum. No difficulty seems to have arisen during this procedure because of the previous arthroplasty.

The final conclusion is that the shelf operation should be included in our armamentarium for dealing with both pain and dysplasia in the adolescent.

\section{REFERENCES}

Albee FH. Orthopedic and reconstruction surgery. Philadelphia: WB Saunders Co, 1919:895-901.

Bosworth DM, Fielding JW, Ishizuka T, Ege R. Hip-shelf operation in adults. J Bone Joint Surg [Am] 1961;43-A:93-106.

Ghormley RK. Use of the anterior superior spine and crest of ilium in surgery of the hip joint. J Bone Joint Surg 1931;13:784-98.

Heyman CH. Long-term results following a bone-shelf operation for congenital and some other dislocations of the hip in children.J Bone Joint Surg $[\mathrm{Am}] 1963 ; 45-\mathrm{A}: 1113-46$.

Hoffa A. The ultimate results of my bloodless re-position of congenital dislocation of the hips. Am J Orthop Surg 1905;2:234-9.

Konig. Bildung einer knöchernen Hemmung für den Gelenkkopf bei kongenitaler Luxation. Zentralbl Chir 1891;18:Beilage 26:146-7.

Lomí̌ek M, Stryhal F, Cech O. Therapeutic results following surgical reconstruction of the acetabular rim. Acta Chir Orthop Traumatol Cech 1977;44:192-200.

Wilson JC Jr. Surgical treatment of the dysplastic acetabulum in adolescence. Clin Orthop 1974;98:137-45. 